\title{
4. KNOWLEDGE AND VALORISATION OF THE PLASTIC LANGUAGE AND OF THE FOLK DECORATIVE MOTIFS IN THE ARTISTIC EDUCATION STUDY PROCESS
}

Olimpiada Arbuz-Spatari ${ }^{60}$

\begin{abstract}
The framework and the reference objectives of the 'Textile art' course signal priority of the student's initiation in the fine arts language theory. It is essential to discover new possibilities to study and apply of fine arts language elements for the purposes of triggering students' creativity. For this purpose, at the course of "Textile art", we will examine the necessity of studying fine arts language, synthesis of creative forms when essentially determining the contents in the process of development of artistic creativity to fine arts education students. In the process of development of artistic creativity in students it is important to study the language elements by selecting and processing artistic elements of nature. The study of the elements of fine arts language contributes to educating and informing the creative personality while choosing and processing the reality in the context of a methodical creative thinking - along with compositional regularities of scale, rhythm, movement and fine arts forms.
\end{abstract}

Key words: elements of the fine arts (plastic) language, decorative motifs, folk ornaments, instruction process

\section{Introduction}

Cognition and valorisation of the fine arts language elements and folk decorative ornaments has preoccupied the following authors: C.Ailincăi, L.Blaga, S.Ciubotaru and I.Ciubotaru, I.Daghi, Z.Dumitrescu, N.Dunăre, H.Focillion, I. Frunzetti , H.Horşia, D.Mihăilescu, D. Mureşean, V.Pavel, A.Pleşu, C.Prut, C.Spânu, G.Stoica, S.Şaranuţa, I.Şuşală, V.Vasilescu, W. Worringer, B . Barhin, Iu. Bojco, O.Golubeva etc.

\section{The study of fine arts language}

Languages, according to D.Mihăilescu are means of individual manifestation, systems of functional communication, set up in a long and complex psychosocial process serving fixing, expression and transfer of information through signs. The author distinguishes sound and visual languages. Visual languages include communicating through painting, graphics, textile art (here including the form as a means of specific expression) (Mihăilescu, 1980, p. 13). Languages possess symbolic nature and values: images, ideas, emotions, sounds, graphisms as well as intelligent beings (Chevalier \& Gheerbrant, 1994, p. 233).

In figurative art, as in the abstract, non-figurative one, the language does not possess only the setting, expression, communication, knowledge and influence functions, but also the information transfer one. Forms as a means of expression, have a load of semantic, aesthetic and emotional information notes

\footnotetext{
${ }^{60}$ Associate Professor PhD., "Ion Creangă” State Pedagogical University from Chișinău, Republic of Moldavia, email: olimpiada123@mail.ru
} 
D.Mureşan $(2000$, p. 5). Or, artistic expression, the product of the creative process, partly reflects better than the language areas of the unconscious sense, says D.Mihăilescu (1980, p. 21). By applying fine arts language, D.Mureşan considers that the artist plasticizes both expressiveness and communication. The language of art which helps to define the shape is determined in the form content creative process (Mureşean, 2000, p. 28). J.Guilford distinguishes four types of information in the fine arts: figurative, symbolic, semantic and behavioral. Of all these, the fundamental type is represented by the figurative one, which is concrete, sensory-perceptive. In the fine arts, the creator originally designs the theme in the semantic form, then implements it in the shaped figure (Roşca, 1981, pp. 111-113).

The specifics of the fine arts language is organically linked to the notion of form, which is defined as the paradigm of language means composing the opera appearance: color, line, volume, etc. Form is the result of the creative process in all its complexity, including the idea that led to the creative idea (Dictionary of arts, 1998, p. 188). Form is to be considered the main means of expression and communication in painting, graphics, decorative art, it is the raw material, the specific manner of handling semantic, aesthetic and emotional information. The artist operates, but also creates new artistic processes, mentions D.Mihăilescu (1980, p. 16) and D.Mureşean asserts that plastic forms with symmetry ratios, asymmetry, unity or harmony, movement etc. mean a certain degree of organization, expression, some notes specific to the created object (Mureșean, 2000, p. 26). Therefore, form comprises structural and visual expression means, presented in our research by the study of plastic language elements, point and line.

The point is the only item with no geometric dimensions, infinitely small, associated to the idea of location, fixity, well-defined, the reference standard within a system or another (Dumitrescu, 1984, p. 67); it is defined as the outcome (static, localized, fixed) of the movement of two lines intersecting in space; the point is to be considered in the hierarchy of geometric concepts as the primary element, underlying the formation of all figures, shapes, volumes, all geometric actions; by the use of the point the geometric stages and processes are made. However, the point is the result of an action at a time when it becomes nonexistent, "is the beginning and the end of the (geometric) movement... the generator of all geometric shapes, moving in the plan or space after a certain law, imposed guiding all the evidence " (Dumitrescu, 1984, p. 70).

Theoretically, the point is invisible because it is devoid of size and virtually negligible in size. The point is the easiest element of form, can be itself a form, or to belong to a form. The point remains the fundamental character of immobility. It seems introvert and charged with an inner tension that is to be exerted on the surrounding space (and its disappearance (tension's) cancels the point, and the line appears) (Dictionary of arts, 1998, p. 74). Certain points are of a particular value (those who belong to a punctual structure) that become by plastic and geometric reasoning, reference points, points of plastic interest or compositional centered identifiable points. The point symbolizes the limit state 
of volume abstractization, the center. It lacks size and is not subject to spatial conditions; it embounss the circle within (Chevalier \& Gheerbrant, 1994, p. 133).

The plastic stain can range from free-form, various and intuitive to other geometrised types - proportionate to the size of circles, triangles, rectangles, and other plastic forms (Dumitrescu, 1984, p. 69). The line has the plastic quality of being broken or curved, flat or space; the line represents a number of elements of artistic expressiveness, researched by the fundamental grammar of the plastic image. The line is the sweep left by a pencil, pen, brush, etc on a support, serving the delimitation of bodies and surfaces; it can have many connotations, depending on the path length, thickness, position, grouping, sequence, location in the artistic image field; it is composed of an unbroken string of points in succession and it may suggest the direction, movement, stability etc. (Dictionary of arts, 1998 p. 255). The line highlights the shape's structure because the contour it traces is a part of the work's form, its composition. Lines are carrying meanings presented in an individual way and are holding incipient semantic meanings, and not of a definitive and unified meaning as D.Mureşan (2000, p. $43,44)$ mentions. There have been established the artistic values for each type of line:

- the straight line is the trajectory of a movable point between two positions on the shortest path;

- the horizontal line is calm and static; a vertical one seems firm, and an oblique seems always dynamic and suggests movement (is upward, if moving from bottom left to top right, or downward if disposed vice versa).

- the broken line seems uneasy; a curved line that develops widely suggests fullness; a flowing line creates the messy impression of agitation (Dictionary of arts, 1998, p. 255).

The line has the constructive and expressive functions; lines can reveal the traits, temperament and sensitivity of the author.

The position of lines. The right horizontal represents resting and calm (Luc Joly), it is "the most concise form of the potentiality for a cold and steady movement" (Kandinsky apud Dumitrescu, 1984, p. 79); the vertical line is associated to the idea of ascension, elevation, aspiration towards superior; is a shortened form of potentiality for a warm and uninterrupted movement; the oblique line (right diagonal) is "the most concise form of the potentiality for the continuous hot-cold movement" (Ibid.).

The curved line, according to the same author, belongs to the living kingdom: all forms and structures that are predestined to growth and movement are marked intimately by the curved line. Compared with the straight line (which is the result of the motion generated by a constant force on a point), the curved line (result of the forces acting simultaneously with different intensities on a point) becomes malleable. In the reflection of artistic expressivity, the curved line represents the female character, great skill, the possibility of avoiding limit-situations, persistence in time and space (Dumitrescu, 1984, p. 83). The curved line becomes an elaborate form: ellipses, spirals, curve after the 
transforming creative process. The graphics of the curved line is much closer to the tracing gesture of the hand and reflects the psychological state of creative personality in the the arts. Pqrticuliarities of the line structure:

linear form - the general appearance of a line, defined as straight, curved, broken, drawn with tools or freehand drawn highlights a specific category of plastic expression belonging to the so-called geometric line;

the line body - the graphic quality of a line that contains, along its length, regarded as unique measurable size, and thickness of the line, that can be consistently and regularly in the situation of the geometric line or modulated and worth in the situation of the line drawn by hand free (artistic line) (Dumitrescu, 1984, p. 85).

The curved line, with its many aspects - open (spirals, parabola, hyperbole, etc.) and closed (plane figures of the circle, ellipse, oval, etc.) provides structural-geometrical stages with a specific plastic expressive content (Chevalier \& Gheerbrant, 1994, p. 44). The semantic is in unity with the syntactic, affirms D.Mureşan: the semantic elements is pictured by artistic canons and proportions (symmetry, asymmetry, alternation - syntactic structure); the points merge into lines, shapes; the lines integrate into colors and volumes, symmetry or asymmetry, etc. and building a creative vision (Mureşean, 2000, p. $41,44)$. The science signs have a denotative nature with an universal meaning for all those who know the code; The semantics of the art is connotative (Idem, p. 38).

Symbols are placed in the fine arts language in a meaningful context; It is the essence of the imaginative life (reveals the secrets of the unconscious, trigger the hidden springs of action and provides new insights into the unknown and the infinite), so their study is very important to the development of artistic creativity. The symbol is a sign, object, phenomenon that is invested with a special ability to convey ideas, concepts, ideological allusions even more complex than the mere representation, in accordance with a generally accepted code. In fine arts, the visual symbol is a sign with allusive character, reffering to another reality (material or spiritual), than that image depicts. The symbol can be seized and intuitive, when the sign and what it signifies have concrete substance. There are also visual ancient experience repertoire of symbols such as the symbol of color, numerical symbols (Dictionary of arts, 1998, p. 128).

The geometric symbol is conventional by nature, culturally determined, artistic and personal; it is transformed into geometric language which overlaps it and is in connection with the plastic language. Z.Dumitrescu mentions the emotional consistency of the geometric shape justified by the imaginative matrix of the author, figures and geometrical volumes which don't exist concretely in reality, they are the product of human imagination and intelligence (Dumitrescu, 1984, p. 32). The author proposes three categories of symbolic interpretation of figures and geometric shapes:

- geometric symbols with associative value: geometrical figures adopted as the symbol of an idea, a historical, social, religious notion, through an association, 
removed of the structural-geometric motivation of the sign that became a symbol;

- purely conventional symbols in systems recognized and stated as such, such as mathematical, logical, physical, chemical, etc .;

- symbols prevailing in structural and geometric value (Dumitrescu, 1984, p. 34), which is correlated with the elements of fine arts language: the geometric shapes (points, triangle, square, angles, sharp, obtuse) overlap on the elements of fine arts language (square rectangle, spiral etc.).

Conventional-geometrical codes stipulate in the perception psychology plan ideational correspondences such as the point - the idea of locating, marking; Triangle - the idea of dynamism (resulting from vertical force suggested by the sharp point of angles, consecrated sometimes by the scale and the proportion of the closed figure); square - the idea of stability due the order within its own area determined by four right angles and equal sides (Chevalier \& Gheerbrant, 1994, p. 382). In the textile art, geometrical symbols appear frequently in simple languages, uncoded, or witha very approachable cipher that doesn't need special earlier training. Here there is an obvious transformation of the geometric symbol into artistic symbol, aiming at the synthesis (geometricalplastic) of the signs that have become symbols through creation.

The several forms geometrical-artistic above-mentioned are the primordial geometrical-artistic shapes analyzed in the research, being derived from the condition of the straight line. Plastic structures obtained by styling are called ornamental motifs. The decorative ornamental folk art were classified as: abstract (geometrical patterns can be drawn), cosmomorphic, vegetal, zoomorphic, anthropomorphic, social (Table 1).

Table 1. Groups of ornamental motifs in the Romanian folk art

\begin{tabular}{|c|c|c|c|c|}
\hline $\begin{array}{c}\text { Abstract } \\
\text { ornaments }\end{array}$ & $\begin{array}{c}\text { Cosmomorphic } \\
\text { ornaments }\end{array}$ & $\begin{array}{c}\text { Vegetal } \\
\text { ornaments }\end{array}$ & $\begin{array}{c}\text { Zoomorphic } \\
\text { ornaments }\end{array}$ & $\begin{array}{c}\text { Anthropomorphic } \\
\text { ornaments }\end{array}$ \\
\hline & & $(-1)$ & & 墨 \\
\hline & & " & & \\
\hline & & & $L_{B}$ & \\
\hline$\leadsto$ & (3) & & & \\
\hline
\end{tabular}

Abstract ornaments:

- geometrical - point, many points, line, horizontal or vertical lines, superimposed lines;

- freely drawn - broken lines, curves, lines tangled lines intuitive;

- mixed-geometric and freely drawings, geometric and non-geometrical. 


\section{Cosmomorphic ornaments:}

- geometrical - sun, sun flower, star, why reel;

- freely drawn - stars, lightning, rainbow, haystack circumvented by suns;

- mixed - sun in geometric transposition and free drawn, astral motifs, sun compositions.

\section{Vegetal ornaments:}

- geometrical - flower, leaves, corn, tree of life, tree branches, wheel-flower;

- freely drawn - hornbeam leaf and a flower, chestnut leaf, acorn blossom, acacia flower, flower and leaves;

- mixed - non-geometric and geometric floral composition.

\section{Zoomorphic ornaments, including with bird motifs:}

- geometrical - depictions of horses, hawk, cranes, butterflies, roosters, ram horns;

- freely drawn - peacocks, sheep, deer, yoke, bird, snail, rooster, sheep in the wolf's mouth.

\section{Anthropomorphic ornaments:}

- geometrical and freely drawn - compositions with human faces.

\section{Social ornaments:}

- geometrical - peasant dance;

- freely drawn - married couples, dance;

- mixed - depictions of peasants' dance.

L.Blaga notes the existence in Romanians' folk art of a geometrics of simple figurative essence, mostly linear, static, less demanding, discreet, as well as the tendency to geometrize the motifs inspired by the surrounding nature (Blaga, 1969). The developed contents have included four types of stored information, ie figurative or sensory-perceptual information that includes: visual-figurative information, semantic information, symbolic information, behavioral information. Materials about the student workload in training in the artistic education. On creative work of students, I.Şuşală notes that this is reflected in some initial benchmarks, adapted to the specificities of the textile art, such as:

- evaluating the maximum of the creative potency, affirmation of the plastics' structure (composition), predominantly tilted to one of the languages: of the line's, of the the structural form and space;

- applying different techniques and technological processes in the textile arts;

- nature study;

- decorative vision study: one of the ways of treating creative composition (starts with the study of point, decorative line, decorative shape);

- compliance patterns, study the condition of the workshop, watching the quality, not the quantity of work;

- creating synaesthetic possibilities of intense stimulation through active practice, discovery, favoring self-organizing, self-training;

- practicing creative thinking and practical handling through efficient work of each individual (Şuşală, 1993, p. 17, 18). 
Being practiced in various ways and methods of working, with the use of various tools and materials, language elements are tools of creative visual affirmation for any individual. In these circumstances, developing creativity contributes to empowering creative people, facilitating autonomy and enriching social relationships (Idem, p. 21). As characteristics of creative activity of students needed to be acquired in university courses, are the high tonus during the study process and creative product development; expressive expression, enforcement of the composition laws, expressive organization of the elements of fine arts language; individual semantic and syntactic success in which each creative activity achieves the form - content, the way the elements of the fine arts language are stacked, juxtaposed and ordained; selecting and processing of the elements of reality through transformation, stylization, simplification; fine arts language study; the practice of various working methods and procedures may vary, also the use of tools and materials may vary.

To study the elements of the plastic language and decorative ornaments in educational methodology in the development of artistic creativity in students, there are aspects to be taken into consideration:

- determination of a group of elements of fine arts language and plastic forms: point, line, square, diamond, circle etc .;

- investigating and knowledge of symbols and meanings in the textile art through the studied elements of fine arts language: plastics, geometrical, ornamental;

- correlation between elements of fine arts language and plastic forms, geometrical, expressive, intuitive, plastic structures.

In the graph representing the above context, we will use the form-content formula. We noted that the forms specific to the fine arts language contain informations - contents (Figure 1).

Figure 1. The methodology of studying fine arts language

\begin{tabular}{|c|c|c|c|}
\hline \multicolumn{4}{|c|}{$\begin{array}{l}\text { The study of plastic language elements by creative application of the } \\
\text { form- content formula }\end{array}$} \\
\hline 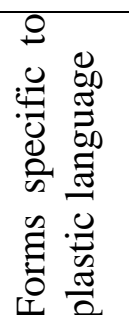 & \begin{tabular}{|l|} 
Plastic \\
Expressive \\
Freely-drawn \\
Intuitive \\
Geometrical \\
Traditional decorative
\end{tabular} & 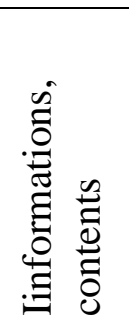 & $\begin{array}{l}\text { Simbolic } \\
\text { Semantic } \\
\text { Iconic } \\
\text { Conotative } \\
\text { Encoded }\end{array}$ \\
\hline
\end{tabular}

The study of fine arts language by applying the form-content formula determines the specific forms of fine arts language and information - contents. For the Specific forms of the fine arts language compartment they are selected and presented in the following order: plastics, expressive, freely drawn, intuitive, geometric, traditional ornaments. For the Informations - contents there are specified the following types: symbolic, linguistic, iconic, connotative, encoded.

\section{Conclusions}

Of the above, we mention that: 
- Development of the artistic creativity by studying plastic language elements represents a form of organization of the creative process;

- The process by which the students may be stimulated is the application of plastic language elements in the the creative process - optimize and raise the aesthetic value of creative works in the the course of textile art. It is a necessary level prior to intercommunication through artistic language;

- Creativity optimization maintains a high tone of creativity during the creative process of learning and developing creative compositions with the conscious application of the plastic language in the creative work in art textiles;

- Gender plastic elements are as follows: expressive expression, compositional regularities, expressive organizing of the elements of visual language. Artistic knowledge are constituted of plastic signs necessary to representations;

- In terms of fine arts language, the meaning of the creative product is given by the the semantic and syntactic success, which includes an individual path in which each creative activity performs the form - content, the way the elements of the plastic language are stacked, juxtaposed and ordained;

- Selection and processing of some reality elements are operations (transformation, stylization, simplification) of elections and processing illustrating an original rendering of reality;

- The fine arts language study is a necessary step prior to intercommunication through artistic language;

- Practiced in various ways and work methods, with various tools and materials, language elements become tools for creative personality affirmation. In this context, developing creativity contributes to empowering creative personalities.

\section{Bibliography}

1. Blaga, L. (1969). Trilogy of culture. Bucharest: Editura pentru Literatura Universală.

2. Chevalier, J. Gheerbrant, A. (1994). Dictionary of symbols (Vols. 1-3). Bucharest: Artemis.

3. Ciubotaru, S., Ciubotaru, I. (1988). Traditional folk ornaments from Moldova (seams, fabrics). Iaşi: Universitatea „Al. I.Cuza”; Centrul de Lingvistică, Istorie Literară şi Folclor, arhiva de folclor a Moldovei şi Bucovinei.

4. Dictionary of arts. Forms, techniques, artistic styles (Vols. 1-2). (1998). Bucureşti: Meridiane.

5. Dumitrescu, Z. (1984). Geometric structures and plastic structures. Bucharest: Meridiane.

6. Mihăilescu, D. (1980). The colours and forms language. Pocket Enciclopaedia. Bucharest: Editura Ştiinţifică şi Enciclopedică.

7. Mureşean, D. (2000). Knowledge and artistic creation with special reference to fine arts. Bucharest: Cybela.

8. Roşca, A. (1981). General and specific creativity. Bucharest: Editura Academiei Române.

9. Şuşală, I. (1993). The every day colour. Chişinău: Lumina.

10. Vasilescu, V. (1993). The signs of the sky. Carpathian culture and civilization. Iaşi: Arhetip-Renaşterea Spirituală. 